\title{
Eruption column height estimation of the 2011-2013 Etna lava fountains
}

\author{
Simona Scollo ${ }^{1,}$, Michele Prestifilippo ${ }^{1}$, Emilio Pecora ${ }^{1}$, Stefano Corradini ${ }^{2}$, Luca Merucci ${ }^{2}$, \\ Gaetano Spata ${ }^{1}$, Mauro Coltelli ${ }^{1}$
}

${ }^{1}$ Istituto Nazionale di Geofisica e Vulcanologia, Osservatorio Etneo, Catania, Italy

${ }^{2}$ Istituto Nazionale di Geofisica e Vulcanologia, Centro Nazionale Terremoti, Rome, Italy

\author{
Article history \\ Received August 14, 2013; accepted February 13, 2014. \\ Subject classification: \\ Volcano monitoring, Eruption column height, Video-surveillance cameras, SEVIRI and MODIS satellites.
}

\begin{abstract}
In this paper, we use calibrated images collected by the video-surveillance system of the Istituto Nazionale di Geofisica e Vulcanologia, Osservatorio Etneo, to retrieve the height of the eruption column during the recent Etna explosive activity. The analysis is carried out on nineteen lava fountains from the New South East Crater dataset. The novel procedure described in this work is achieved in three main steps: at first we calibrated the camera, then we selected the images which recorded the maximum phase of the eruptive activity, and finally we applied an appropriate correction to account for the plume projection on the camera line of sight due to the wind. The results show that the column altitudes range between 6 and $9 \mathrm{~km}$ (upper limit of the camera system). The comparison with the plume height values estimated from the analysis of several SEVIRI and MODIS satellite images, show a good agreement. Finally, for nine events we also evaluated the thickness of the volcanic plumes in the umbrella region which ranges between 2 and $3 \mathrm{~km}$.
\end{abstract}

\section{Introduction}

The column height estimation is an essential parameter to evaluate the Volcanic Explosive Index [Newhall and Self 1982], the total mass eruption rate [Sparks et al. 1997], the plume dispersal [Bonadonna et al. 2012] and the plume gas and aerosol retrievals [Prata and Grant 2001]. In general, the column height may be estimated by using different methods (e.g. satellite, aircrafts and ground observations) which may present, in some circumstances, marked differences [Tupper and Wunderman 2009]. Multispectral images, either aboard on polar (e.g. MODIS) or geostationary (e.g. SEVIRI) satellite platforms, are extensively used to obtain quantitative parameters of volcanic plumes [Corradini et al. 2010, Merucci et al. 2011] and are a valuable tool to estimate the column height. SEVIRI images are collected every 5 or $15 \mathrm{~min}$ and, during a volcanic crisis, are often used by volcano observatories [Scollo et al. 2009] and Volcanic Ash Advisor Centers (VAAC) to provide fast answers on the plume dispersal. Although some limitations do exist (e.g. presence of water vapor), satellite imagery technique is surely the most widely used method to estimate the column height. Concerning the ground-based observations, they are mainly based on Radar [e.g. Petersen et al. 2013] and Lidar [e.g. Pisani et al. 2012] systems which, however, are very expensive. Conversely the video-surveillance cameras extensively used for volcanic activity monitoring are much cheaper and easier to operate, but still underused to this purpose. Quantitative height estimations from video images are rare, with few examples available in literature. Visual data were applied to Sakurajima [Kinoschita 1996] and Etna [Andronico et al. 2008] volcanoes. Column height errors up to $20 \%$ obtained from video-surveillance systems and photos of the Istituto Nazionale di Geofisica e Vulcanologia, Osservatorio Etneo (INGVOE) were estimated [Scollo et al. 2008], although under some conditions which should be always satisfied. In particular, the plume height should be taken from a sufficient distance from the vent [Sparks et al. 1997] in order to see the plume top and to reduce the obliquity of the image plane. Observations should be specified whether the height is given above the vent or above sea level (a.s.1.) as these two are often misinterpreted [Sparks et al. 1997]. Furthermore, the measurement accuracy should be associated to any column height value [Settle 1978]. In this paper, we describe at first the eruptive activity in 2011-2013, the video-surveillance system, the calibration procedure and the method applied to estimate the column height. Then, we compare our results with the volcanic plume heights estimated by the 
nearly simultaneous data collected from SEVIRI and MODIS satellite instruments. Finally, we discuss the advantages of the proposed approach and the future improvements.

\section{The 2011-2013 Etna lava fountains}

Between 12 January 2011 and 27 April 272013 Etna produced 38 basaltic lava fountains from a new volcanic vent opened on the eastern flank of the South East Crater. The eruptive episodes were characterized by a paroxysmal phase which lasted on average about one hour, and were preceded by mild strombolian activity and often by lava flow. Every paroxysm formed an eruption column ranging from five to about ten kilometers of height and tephra fallout was mainly spread out on the eastern sectors of the volcano. Volcanic ash dispersed in atmosphere, contaminated the air space of the international airport of Catania causing troubles to air traffic operations, and sometimes forced the airport closure during the activity.

\section{Methods}

The monitoring of eruptive activity is continuously carried out at Etna using a system of video-surveillance cameras located on the southern and eastern flanks of the volcano [Andò and Pecora 2006]. The cameras record the visible and infrared bands and are located in Catania (ECV, $27 \mathrm{~km}$ from the vent), Milo (EMV, $11 \mathrm{~km}$ from the vent), Nicolosi (ENV and ENT, $15 \mathrm{~km}$ from the vent), Schiena dell'Asino (ESV, $5 \mathrm{~km} \mathrm{SE}$ from the vent), Monte Cagliato (EMCT, $8 \mathrm{~km}$ E from the vent) and La Montagnola (EMOV and EMOT, $3 \mathrm{~km}$ SE from the vent). All the images are acquired, digitized, and archived at the INGV-OE site and displayed in the $24 / 7$ control room of INGV-OE. In our study we use images taken by the ECV camera $\left(15.0435^{\circ} ; 37.5138^{\circ}\right)$. We analyzed all the ECV images of the 38 lava fountains in the visible range collected between 2011 and 2013. Thus, the eruptive events that occurred during the night or in overcast weather were excluded. For each selected event, an image was taken during the maximum of the paroxysmal phase in order to evaluate the maximum column height. The calibration was carried out using the Camera Calibration (http:/ / www.vision.cal tech.edu/bouguetj/lib_doc/) Toolbox for Matlab and images of a calibration pattern (Figure 1), estimating the intrinsic parameters of the camera [Zhang 1999]. Hence, using geographically known features (e.g. the location of the NE crater, Rifugio Sapienza), we estimate the full camera model in order to locate in the image, any point in the space of the camera field of view.

We note that a specific camera image point can be anywhere on the line of sight, making impossible the

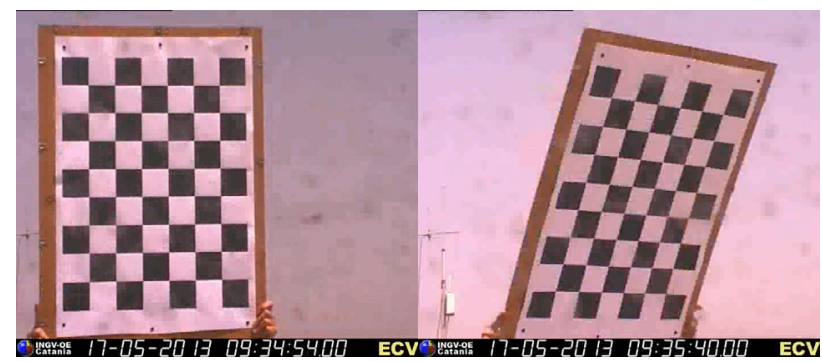

Figure 1. The pattern used for the camera calibration.

evaluation of a reliable column height without adding at least one geometrical constraint. In our case, the simpler constraint is a vertical plane passing through the volcanic vent and parallel to the wind direction (e.g. the main plume spreading direction). In particular, we used the daily weather forecast [Scollo et al. 2009] to identify the plane containing the plume axis. Consequently we were able to measure the geometry of the plume (Figure 2). We evaluated an error of $\pm 0.5 \mathrm{~km}$, which is equal to the space among the green lines in Figure 2.

The column height was also evaluated from satellite images nearly simultaneous to the video camera measurements. We used the data collected from SEVIRI and MODIS, and estimated the volcanic plume height following Corradini et al. [2010].

This procedure is based on the comparison between the $11 \mu \mathrm{m}$ brightness temperature $\left(\mathrm{T}_{\mathrm{b}, 11}\right)$ of the

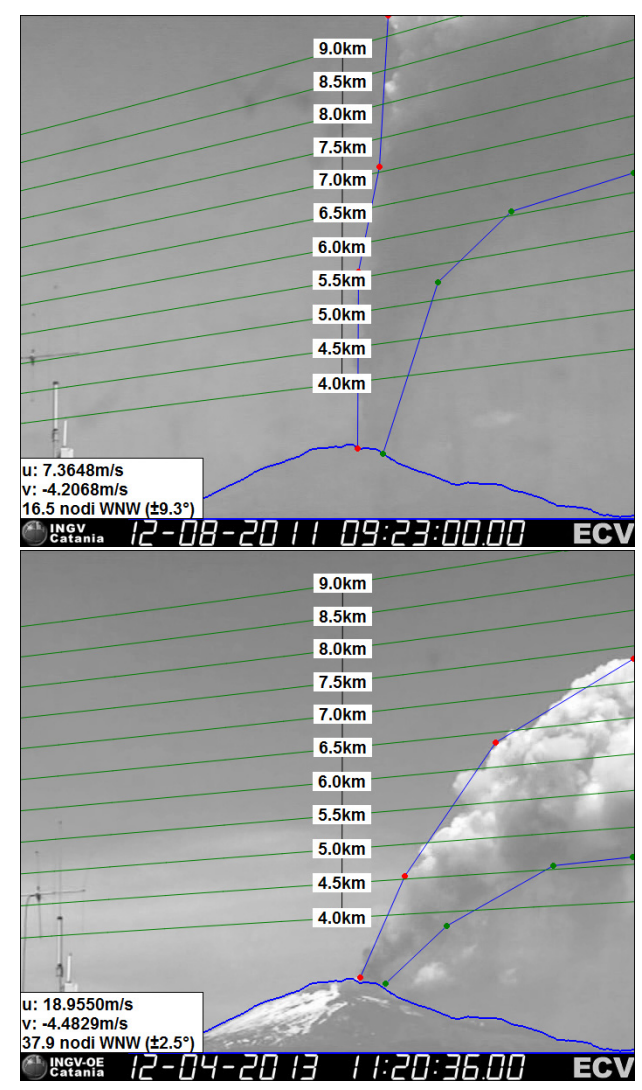

Figure 2. Two examples of the calibrated ECV images used to estimate the height. The green lines indicate the height a.s.l. The line angle is function of the wind direction. 

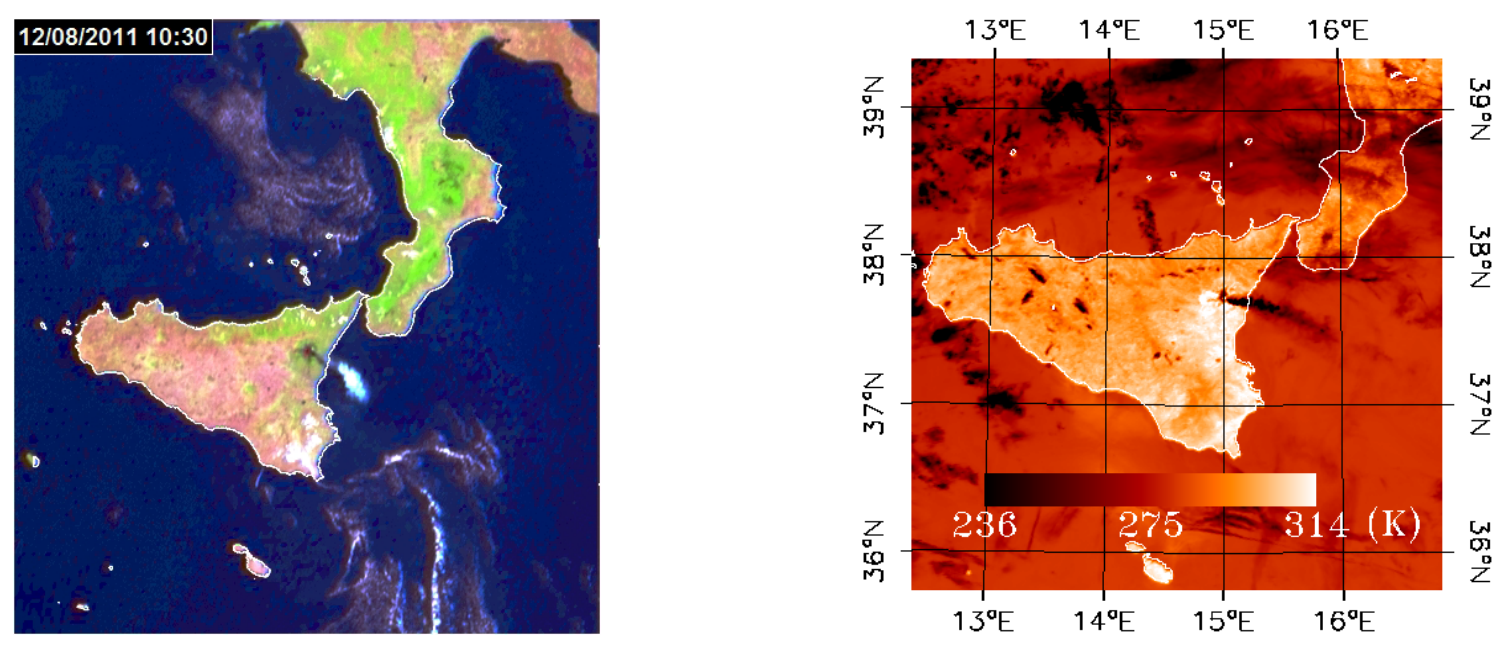

Figure 3. SEVIRI image of $12 / 08 / 2011$ and MODIS-Terra brightness temperature map at $11 \mu \mathrm{m}$ used to estimate the plume column height of 12/04/2013 (12:00 UTC).

SEVIRI/MODIS most opaque pixels (Figure 3) with the temperature profile extracted from the WMO radiosoundings of Trapani (http://weather.uwyo.edu/).

The altitude retrieval error is estimated by considering a brightness temperature uncertainty of $+/-2 \mathrm{~K}$ [Prata and Grant 2001].

\section{Results}

Table 1 shows column height values for nineteen lava fountain events evaluated by the video-surveillance and satellite images. Seven events with column heights less than the maximum height $(9 \mathrm{~km})$ measurable from the ECV images, were well constrained by the camera.

\begin{tabular}{|c|c|c|c|c|}
\hline \multirow{2}{*}{$\begin{array}{c}\text { Date } \\
\text { (dd-mm-yy) }\end{array}$} & \multicolumn{2}{|c|}{ ECV } & \multirow{2}{*}{$\begin{array}{c}\text { SEVIRI } \\
\text { H (km); h (UTC) }\end{array}$} & \multirow{2}{*}{$\begin{array}{c}\text { MODIS } \\
\mathrm{H}(\mathrm{km}) ; \mathrm{h} \text { (UTC) }\end{array}$} \\
\hline & H (km); h (UTC) & $\mathrm{T}(\mathrm{km})$ & & \\
\hline $10-04-11$ & $>9.0 ; 11: 18$ & & $6.1 \pm 0.4 ; 11: 15$ & \\
\hline $10-04-11$ & & & $6.3 \pm 0.4 ; 12: 30$ & $7.8 \pm 0.3 ; 12: 30$ \\
\hline 09-07-11 & $>9.0 ; 14: 30$ & & $8.2 \pm 0.3 ; 15: 00$ & \\
\hline $12-08-11$ & $>9.0 ; 09: 23$ & & $8.5 \pm 0.5 ; 09: 30$ & \\
\hline $12-08-11$ & $6.5 \pm 0.5 ; 11: 15$ & & $7.2 \pm 0.5 ; 11: 15$ & $7 \pm 0.3 ; 11: 15$ \\
\hline $20-08-11$ & $>9.0 ; 07: 12$ & 3.0 & $9.3 \pm 0.6 ; 07: 45$ & \\
\hline 29-08-11 & $>9.0 ; 04: 40$ & 2.5 & $7.8 \pm 0.4 ; 04: 30$ & \\
\hline 08-09-11 & $>9.0 ; 08: 11$ & & $10.9 \pm 0.4 ; 08: 15$ & $9.7 \pm 0.3 ; 9: 20$ \\
\hline 19-09-11 & $5.0 \pm 0.5 ; 12: 52$ & & Cloudy & \\
\hline $08-10-11$ & $7.5 \pm 0.5 ; 14: 51$ & 3.0 & Cloudy & \\
\hline $15-11-11$ & $>9.0 ; 12: 18$ & 2.5 & $9.9 \pm 0.4 ; 12: 15$ & $11.1 \pm 0.3 ; 12: 10$ \\
\hline $05-01-12$ & $>9.0 ; 06: 20$ & & $7.2 \pm 0.4 ; 06: 15$ & \\
\hline $09-02-12$ & $8.0 \pm 0.5 ; 05: 45$ & 2.0 & $7.9 \pm 0.5 ; 05: 45$ & \\
\hline $04-03-12$ & $>9.0 ; 08: 31$ & & $8.9 \pm 0.4 ; 08: 30$ & $9.5 \pm 0.6 ; 9: 10$ \\
\hline $04-03-12$ & $8.0 \pm 0.5 ; 09: 00$ & & $7.9 \pm 0.4 ; 09: 00$ & \\
\hline $18-03-12$ & $>9.0 ; 09: 16$ & & $9.2 \pm 0.5 ; 09: 30$ & $11 \pm 2.3 ; 9: 20$ \\
\hline $12-04-12$ & $6.5 \pm 0.5 ; 14: 30$ & 3.0 & $6.7 \pm 0.5 ; 14: 40$ & \\
\hline $12-04-12$ & $8.0 \pm 0.5 ; 15: 00$ & 3.0 & $7.5 \pm 0.5 ; 15: 00$ & \\
\hline $28-02-13$ & $>9.0 ; 10: 31$ & & $9.4 \pm 0.3 ; 10: 30$ & \\
\hline 03-04-13 & $7.5 \pm 0.5 ; 14: 19$ & 3.0 & $5.6 \pm 0.6 ; 14: 20$ & \\
\hline 03-04-13 & $6.0 \pm 0.5 ; 14: 45$ & 3.0 & $5.8 \pm 0.6 ; 14: 45$ & \\
\hline $12-04-13$ & $7.5 \pm 0.5 ; 11: 20$ & 3.0 & $7.2 \pm 0.4 ; 11: 45$ & $7.3 \pm 0.3 ; 12: 00$ \\
\hline $18-04-13$ & $>9.0 ; 12: 18$ & & $6.9 \pm 0.4 ; 12: 35$ & \\
\hline $27-04-13$ & $8.5 \pm 0.5 ; 18: 18$ & 3.0 & Cloudy & \\
\hline
\end{tabular}

Table 1. Column height $(\mathrm{H})$ a.s.l. estimated from the calibrated video frames (ECV), SEVIRI and MODIS data for lava fountain events. Cloud thickness $(\mathrm{T})$ is indicated when measurable, along with measurement time $(\mathrm{h})$. 
For some events, we could also estimate the cloud thickness by tracking the base of the plume on the ECV images (Table 1). Events for which the column height is greater than $9 \mathrm{~km}$ were $29 / 08 / 2011,8 / 09 / 2011$, $15 / 11 / 2011,5 / 01 / 2012,18 / 03 / 2012$, while for events 10/04/2011, 09/07/2011, 12/08/2011, 20/08/2011, $04 / 03 / 2012,28 / 02 / 2013,18 / 04 / 2013$, the estimated column height doesn't differ greatly from $9 \mathrm{~km}$. It is worth to note that marked height differences between video camera and MODIS estimates are mainly due to the time shift of the satellite image acquisition with respect to the video frame. As the volcanic activity is highly variable, we also evaluated the column heights near the MODIS overpass (Table 1). For instance, on 12/08/2011 MODIS collected data on Etna at 11:15 UTC while the ECV image of the maximum height reached during the event was acquired at 9:23 UTC. At 11:15 UTC the eruptive activity sensibly decreased, but the column height measured from the ECV at the same time was $6.5 \mathrm{~km}$, thus very close to the MODIS estimation.

\section{Discussion and conclusion}

In this paper we show how the column height may be quantitatively estimated using the video-surveillance images. However, the camera calibration and the correction accounting the projection of the plume on the camera line of sight direction are two essential steps. The unbiased measurement is when the wind blows in a direction orthogonal to the line of sight (i.e. eastward because the camera is located on the south flank of Etna). Furthermore, if the wind direction is constant with height the plane crossing the volcanic vent is well defined, and the error on the extrapolation of the column height is consequently low. Another estimation that can be obtained with the proposed method is the volcanic plume thickness, an extremely valuable information for the satellite plume ash and gas retrievals [Corradini et al. 2010] that can be currently obtained only if lidar and radar data are available. We highlight that height estimations obtained by video-surveillance images and satellites are in very good agreement. Worst cases are 10/04/2011,3/04/2011 and 18/04/2011. Here we note that the volcanic plumes are small if compared to the SEVIRI spatial resolution, and the pixels used to compute the brightness temperature are not completely opaque. Furthermore, the satellite plume height error is underestimated because the temperature profile spatial variability is not taken into account (the Trapani WMO radiosounding station is about 250 $\mathrm{km}$ from the volcanic vents). Differences may depend also from the fact that video camera and satellites do not see the same eruptive scene. The main limitations of the proposed method are: i) wind data used in this study are derived from wind-field forecasts [Scollo et al. 2009], but for other volcanoes similar data might be unavailable; ii) column height measurements using visible cameras cannot be applied during the night or bad weather conditions; iii) limit of the INGV-OE camera that cuts the column heights that are greater than $9 \mathrm{~km}$ a.s.l. Our future work will concern the column height estimation as a function of time to better understand the short-term variations which often characterize basaltic lava fountains. We note that the column height is an extremely valuable information during an eruptive crisis to reduce the aviation hazard and mitigate the tephra fallout risk for inhabited areas close to volcanoes by mean of plume dispersal forecasting. The proposed method could be introduced in the $24 / 7$ surveillance system of INGV-OE to support quantitative descriptions of the eruptive phenomena used for writing the VONA (Volcano Observatory Notice for Aviation) message. Finally, our method could be applied to other visible and IR cameras which should be installed farther from the vents, and preferably on the north and south flanks of volcano perpendicular to the prevailing wind direction which is, on Etna region, from the west to the east.

Acknowledgements. We greatly thank E. Biale, F. Ciancitto, F. Donnadieu, the anonymous reviewers. This work was funded by the SMASH project funded by ESA and by the MED-SUV project funded from the European Union's Seventh Programme for research, technological development and demonstration under grant agreement No. 308665 .

\section{References}

Andò, B., and E. Pecora (2006). An advanced video-based system for monitoring active volcanoes, Comput. Geosci., 32, 85-91.

Andronico, D., S. Scollo, A. Cristaldi and S. Caruso (2008). The 2002-2003 Etna explosive activity: Tephra dispersal and features of the deposit, J. Geophys. Res., 113, B04209; doi:10.1029/2007JB005126.

Bonadonna, C., A. Folch, S. Loughlin and H. Puempel (2012). Future developments in modelling and monitoring of volcanic ash clouds: Outcomes from the first IAVCEI-WMO workshop on Ash Dispersal Forecast and Civil Aviation, B. Volcanol., 74, 1-10.

Corradini, S., L. Merucci, A.J. Prata and A. Piscini (2010). Volcanic ash and $\mathrm{SO}_{2}$ in the 2008 Kasatochi eruption: Retrievals comparison from different IR satellite sensors, J. Geophys. Res., 115, D00L21; doi:10.10 29/2009JD013634.

Kinoschita, K. (1996). Observation of flow and dispersion of volcanic clouds from Mt. Sakurajima, Atmos. Environ., 30, 2831-2837.

Merucci, L., M. Burton, S. Corradini, G.G. Salerno (2011). Reconstruction of $\mathrm{SO}_{2}$ flux emission chronology 
from space-based measurements, J. Volcanol. Geoth. Res., 206, 80-87.

Newhall, C.G., and S. Self (1982). The volcanic explosivity index (VEI): an estimate of explosive magnitude for historical volcanism, J. Geophys. Res., 87, 1231-1238.

Petersen, G.N., H. Bjornsson, P. Arason and S. von Löwis (2013). Two weather radar time series of the altitude of the volcanic plume during the May 2011 eruption of Grímsvötn, Iceland, Earth Syst. Sci. Data, 4, 121-127.

Pisani, G., A. Boselli, M. Coltelli, G. Leto, G. Pica, S. Scollo, N. Spinelli and X. Wang (2012). Lidar calibrated depolarization measurement of fresh volcanic ash from Mt. Etna, Atmos. Environ., 62, 34-40.

Prata, A.J., and I.F. Grant (2001). Retrieval of microphysical and morphological properties of volcanic ash plumes from satellite data: Application to Mt. Ruapehu, New Zealand, Q. J. R. Meteorol. Soc., 127 (576B), 2153-2179.

Scollo, S., A. Folch and A. Costa (2008). A parametric and comparative study on different tephra fallout models, J. Volcanol. Geoth. Res., 176, 199-211.

Scollo, S., M. Prestifilippo, G. Spata, M. D'Agostino and M. Coltelli (2009). Forecasting and monitoring Etna volcanic plumes, Nat. Hazards Earth Syst. Sci., 9, 1573-1585; doi:10.5194/nhess-9-1573-2009.

Settle, M. (1978). Volcanic eruption clouds and the thermal power output of explosive eruptions, J. Volcanol. Geoth. Res., 3, 309-324.

Sparks, R.S.J., M.I. Bursik, S.N. Carey, J.S. Gilbert, L.S. Glaze, H. Sigurdsson and A.W. Woods (1997). Observations and interpretation of volcanic plumes, In: R.S.J. Sparks et al. (eds.), Volcanic Plumes, John Wiley, Chichester, UK, 117-140.

Tupper, A., and R. Wunderman (2009). Reducing discrepancies in ground and satellite-observed eruption heights, J. Volcanol. Geoth. Res., 186, 22-31.

Zhang, Z. (1999). Flexible Camera Calibration by Viewing a Plane from Unknown Orientations, In: The Proceedings of the Seventh IEEE International Conference on Computer Vision (ICCV), 666-673.

\footnotetext{
^Corresponding author: Simona Scollo,

Istituto Nazionale di Geofisica e Vulcanologia, Sezione di Catania, Osservatorio Etneo, Catania, Italy; email: simona.scollo@ct.ingv.it. 